Int. J. Odontostomat.,

7(3):343-349, 2013.

\title{
Efecto Inmediato de Infusiones de Consumo Habitual en las Propiedades Salivales
}

\author{
Immediate Effect of Commonly Consumed Infusions in the Salivary Properties
}

\author{
Carlos Larrucea V.,"*; Erika Henríquez O.."; Monserrat Inostroza T."; Laura Campos M.."; \\ Carolina Peña G."; Carlo Larrucea S.,"*; Miguel Arenas S.,"* \& Karina Larrucea S.,"*
}

\begin{abstract}
LARRUCEA, V. C.; HENRÍQUEZ, O. E.; INOSTROZA, T. M.; CAMPOS, M. L.; PEÑA, G. C.; LARRUCEA, S. C.; ARENAS, S. M. \& LARRUCEA, S. K. Efecto inmediato de infusiones de consumo habitual en las propiedades Salivales. Int. J. Odontostomat., 7(3):343-349, 2013.

RESUMEN: Gran cantidad de población consume cotidianamente infusiones, como el Té, Manzanilla y Yerba Mate. Diferentes estudios han determinado sus efectos benéficos en los seres humanos, razón por la cual, para este estudio se han seleccionado aquellas infusiones de uso habitual con el fin de caracterizar sus efectos inmediatos sobre las propiedades de la saliva. Con grupos de 37 sujetos sanos, entre 18-23 años, de bajo riesgo cariogénico se obtuvieron 3 muestras de saliva no estimulada: Basal; Post-ingesta de Agua Destilada (Placebo) y Post-ingesta Infusión (Té Negro, Té Verde, Mate, Manzanilla y Manzanilla con Endulzante), respectivamente. Todas las pruebas fueron realizadas bajo condiciones estándar. Se determinó el flujo salival (ml/min), pH mediante pH-metro (PL-600, GOnDO Electronics Co, TW) y capacidad buffer mediante método de Ericsson. Todos los datos se procesaron mediante la prueba ANOVA con el programa Origin 6.0. El promedio de Flujo Salival Basal $(0,51 \mathrm{ml} / \mathrm{min})$ tiende a aumentar destacando el efecto de la Manzanilla con Endulzante $(0,63 \mathrm{ml} / \mathrm{min})$; el pH basal $(7,25)$ se mantuvo relativamente constante, y la Capacidad Buffer $(4,38)$ también tiende a aumentar destacando la Manzanilla $(5,01)$. El efecto de algunas infusiones es positivo sobre las propiedades salivales, destacando la Infusión de Manzanilla, Manzanilla con Endulzante y Yerba Mate las cuales aumentan significativamente el flujo y la capacidad buffer salival, lo cual sugiere un efecto benéfico en la prevención de caries.
\end{abstract}

PALABRAS CLAVE: flujo salival, pH, capacidad buffer, té, manzanilla, mate.

\section{INTRODUCCIÓN}

La Organización Mundial de la Salud define la caries dental como una enfermedad infectocontagiosa (García-Godoy \& Hicks, 2008), producida por la concurrencia de bacterias específicas, un huésped susceptible y un ambiente adecuado, como es la cavidad oral. La caries como patología se encuentra presente a lo largo de la historia del hombre, siendo un grave problema de salud pública en la mayor parte de los países industrializados (Beauchamp et al., 2008). La desmineralización de los dientes ocurre a un $\mathrm{pH}$ entre 5,0 y 5,5 , y se ha reportado que la solubilidad de los tejidos dentarios se incrementa en un factor de 7 a 8 por cada unidad que disminuye el $\mathrm{pH}$, con un incremento en el riesgo de desmineralización (Heintze et al., 1983; Stookey, 2008; Stookey et al., 2011).
Uno de los compuestos más efectivos de protección del esmalte dentario contra los ácidos es la saliva, a la cual se le atribuyen una amplia gama de roles en el equilibrio y mantención de la salud oral y actividad anticariogénica, principalmente mediante la limpieza de azúcares y capacidad buffer (tamponante) (Azrak et al., 2003; Fenoll-Palomares et al., 2004).

Esta propiedad tamponante de la saliva es clave durante el proceso carioso, evitando disminuciones violentas en el $\mathrm{pH}$ salival y acidificación del medio, lo que detiene el proceso de desmineralización, mecanismo que se ve potenciado por el incremento de la secreción salival debido al cambio acidogénico (Bardow et al., 2000; Stookey).

\footnotetext{
* Rehabilitación Oral, Fisiología Oral, Universidad de Talca, Talca, Chile.

" Fisiología Oral, Universidad de Talca, Talca, Chile.

Proyecto Parcialmente Financiado por Dirección de Programas de Investigación DPI I001148.
} 
Dentro de las sustancias que podrían favorecer las propiedades beneficiosas de la saliva, se encuentran las infusiones de uso habitual como el Té, la Manzanilla y el Mate. El Té, en sus variedades Negro y Verde han demostrando tener efectos favorables como el aporte de fluoruros, la inhibición en la síntesis de glucanos y crecimiento de Streptococcus mutans, la actividad de la amilasa salival, y la reducción en la producción de maltosa hasta en un $70 \%$ (Simpson et al., 2001; McKay \& Blumberg, 2002; Valenzuela, 2004; Zhu et al., 2006). La Yerba Mate reporta indicios de acción antibacteriana, específicamente contra Streptococcus mutans (López de Bocanera et al., 1999; Burris et al., 2012). Los efectos de la Manzanilla han sido menos estudiados sobre la cavidad oral, sin embargo se encuentra presente en pastas y enjuagues bucales, principalmente debido a sus propiedades antiinflamatorias (Vinson, 2000; Szoke et al., 2004; Llena-Puy, 2006).

Las evidencias sustentan la hipótesis de que el consumo de Infusiones puede ser efectivo en la reducción del potencial cariogénico que presentan algunos alimentos, modificando de manera benéfica las propiedades de la saliva.

\section{MATERIAL Y MÉTODO}

Se realizó un estudio sobre una muestra por conveniencia, comprendida por grupos de 37 estudiantes Universitarios. Se incluyeron sujetos de entre 19 y 23 años, sin enfermedades sistémicas y con bajo riesgo cariogénico, determinado por examen clínico realizado por dos odontólogos previamente calibrados con una concordancia de 0.8 , según la prueba Kappa, basado en el software "Cariogram, Evaluation of the Caries Risk", seleccionando para las muestras los sujetos que obtengan un bajo riesgo cariogénico en su interpretación preliminar y medidas propuestas (Preliminary Interpretation and Proposed Measures). Fueron excluidos quienes presentaran caries abierta, enfermedad periodontal, ingesta de medicamentos que alteren el flujo salival, tratamiento con anticonceptivos orales, ingesta de alcohol por 5 días previo a la prueba in vivo, hábito de fumar (se consideró como fumador cuando el sujeto señaló hábito activo, independientemente del número de cigarrillos/día). Todas las pruebas se realizaron entre las 10:00 am y 14:00 pm a temperatura ambiente $\left(20^{\circ} \mathrm{C}\right.$ promedio), donde se solicitó a los sujetos abstenerse de comer y cepillar sus dientes por lo menos 60 minutos previos al proce- dimiento (Bardow et al.; Fenoll-Palomares et al.; Lamanda et al., 2007).

Se determinaron los parámetros basales, de flujo salival, $\mathrm{pH}$ y capacidad buffer mediante muestras de saliva no estimulada, donde cada sujeto depositó saliva por 15 minutos en tubos Falcon estériles milimetrados de $10 \mathrm{ml}$ (Fig. 1A). El flujo salival se determinó dividiendo la cantidad de saliva $(\mathrm{ml})$ por los 15 minutos que duró el proceso de recolección. El pH se registró utilizando un electrodo ( $\mathrm{pH}$ electrode $0-14 \mathrm{pH}$, 0-90 ${ }^{\circ} \mathrm{C}-\mathrm{PE}-149 \mathrm{G}$ ) conectado a un $\mathrm{pH}$-metro (GOnDO Bench Top pH-mV-Temperature Meter - PL-600Lab), calibrado al inicio de cada sesión utilizando buffer estándar de $\mathrm{pH} \mathrm{4,0}$ y 7,0. En todos los registros el electrodo se dejó el tiempo necesario hasta que se estabilizó la medición, indicada por el mismo instrumento (aproximadamente $20 \mathrm{seg}$ ), y luego se registró el pH (Fig. 1B). Entre lecturas de pH, el electrodo fue irrigado y colocado en agua destilada entre cada medición para evitar su contaminación. Antes de realizar cada nueva medición, este fue secado con toallas de papel suave desechables. Posteriormente se determinó la capacidad buffer de la saliva mediante el método de Ericsson para saliva no estimulada. Este método requiere de una solución de $\mathrm{HCl} 0,003 \mathrm{M}$, la que se obtuvo por dilución desde una solución de $\mathrm{HCl}$ 12,01 M. Se extrajeron $2 \mathrm{ml}$ de saliva de la muestra obtenida de los sujetos y se utilizaron $6 \mathrm{ml}$ de $\mathrm{HCl} 0,003 \mathrm{M}$, estas cantidades fueron duplicadas en relación al método de Ericsson para obtener un mayor volumen de muestra y facilitar la medición del pH-metro (Fig. 1C). Sobre la solución obtenida, se incorporó una barra magnética a los vasos precipitados para llevarlo a un agitador magnético durante 20 minutos, para luego medir el $\mathrm{pH}$ y así determinar la capacidad buffer de la muestra.

En otra sesión, en iguales condiciones, se midió flujo salival, $\mathrm{pH}$ y capacidad buffer salival, de saliva recolectada un minuto después de beber un vaso de $200 \mathrm{ml}$ de agua destilada a $50^{\circ} \mathrm{C}$ (control placebo) en un promedio de tiempo de $5 \mathrm{~min}$.

Finalmente las infusiones utilizadas, fueron seleccionadas entre las marcas comerciales de uso común, que presentaran un comportamiento estable entre si respecto al $\mathrm{pH}$. Las infusiones de Té Negro, Té Verde y Manzanilla fueron bolsas comerciales, en el caso de la Manzanilla con Endulzante se utilizaron 2 comprimidos de Sucralosa, y el Mate se proporcionó según su uso común. Se colocaron en el interior de vasos de poliestireno expandido (plumavit), con 200 

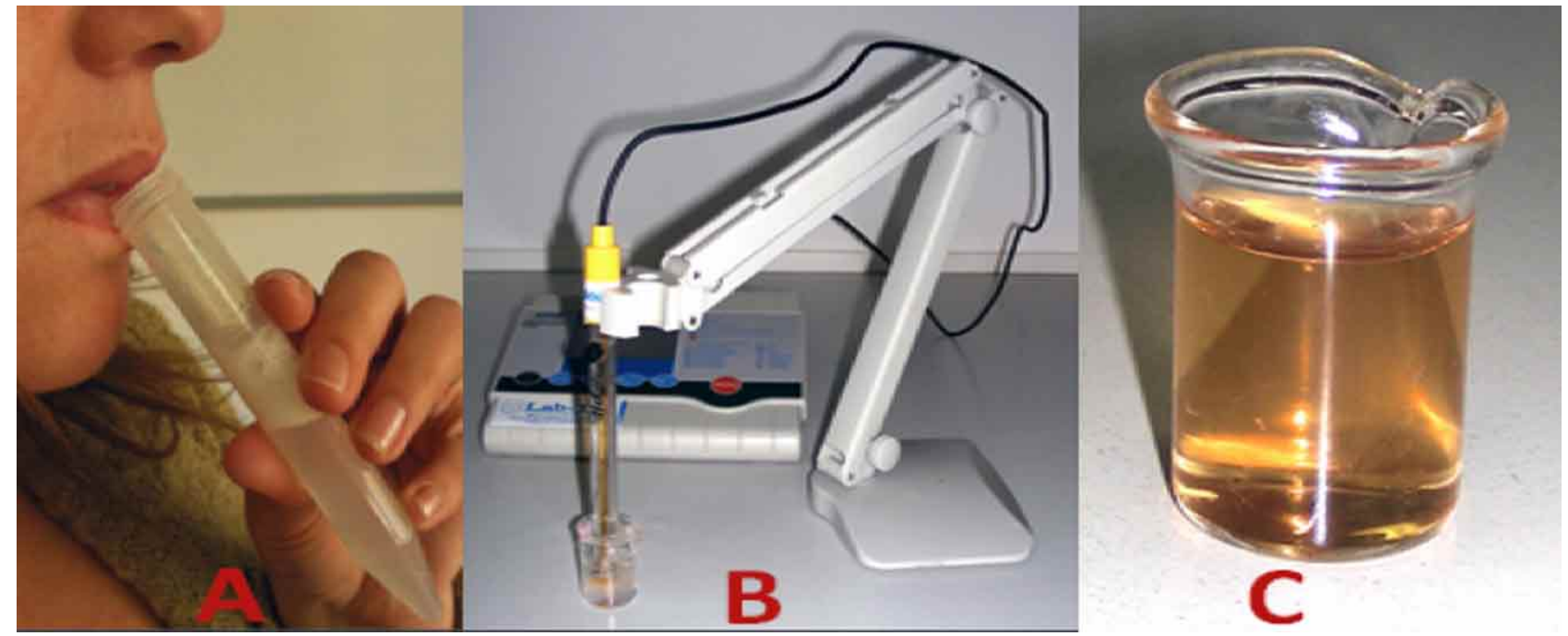

Fig. 1. Medición de Flujo (A), pH (B) y Capacidad Buffer Salival (C).

$\mathrm{ml}$ de agua a $100^{\circ} \mathrm{C}$, donde fueron monitoreadas con termómetro digital, hasta alcanzar los $50^{\circ} \mathrm{C}$. Al llegar a esta temperatura se mantuvo la infusión en un baño térmico a igual temperatura. En diferentes sesiones se les entregaron a los sujetos las diferentes infusiones para su consumo en un promedio de 5 minutos. Luego de esto se recolectó la saliva con el protocolo i anterior y se determinó flujo, $\mathrm{pH}$ y capacidad buffer de saliva no estimulada.

\section{RESULTADOS Y DISCUSIÓN}

Todas las muestras salivales obtenidas fueron válidas, y los valores de Flujo Salival, pH y Capacidad Buffer coincidieron con los descritos en la literatura y corresponden con valores para sujetos sanos con bajo riesgo cariogénico (Ericson \& Bratthall, 1989; Humphrey \& Williamson, 2001; de Almeida et al., 2008).
Los promedios, desviación estándar (DE) y error estándar (EE) de los datos recolectados, posterior al consumo de las diferentes Infusiones fueron:

Flujo Salival: incremento marcado en sus promedios la Yerba Mate $(0,52 \mathrm{ml} / \mathrm{min})$, Manzanilla $(0,53 \mathrm{ml} / \mathrm{min}) \mathrm{y}$ Manzanilla con Endulzante $(0,63 \mathrm{ml} / \mathrm{min})$ (Tabla I); se observa que tanto la infusión de Yerba Mate como la de Manzanilla incrementan el flujo salival con diferencias significativas $(p \geq 0,05)$, destacando el aumento del flujo generado por la Manzanilla con Endulzante $(p \geq 0,01)$ (Fig. 2). El flujo salival, post ingesta de Té Verde se ve recuperado a valores cercanos a los basales, y el Té Negro presentó una leve disminución. Al compararlo con la muestra control, ambas presentan un aumento en el flujo. Esto puede deberse a que el té, al poseer aroma y sabor astringente produce en la boca una sensación de sequedad y amargor, aumentada al no estar endulzado, el cual, genera un estímulo gustativo mayor que al beber algo insípido como el agua (de Oliveira et al., 1997).

Tabla I. Flujo Salival posterior a la Ingesta de Infusiones, Promedios, Desviación Estándar (DE) y Error Estándar (EE).

\begin{tabular}{lcccccc}
\hline & & Promedio & \pm DE & \pm EE & Min. & Max. \\
\hline Basal & {$[1: 37]$} & 0,51243 & 0,16096 & 0,02646 & 0,26 & 0,86 \\
Control & {$[1: 37]$} & 0,38568 & 0,19307 & 0,03174 & 0,12 & 0,86 \\
Té Negro & {$[1: 37]$} & 0,47216 & 0,18710 & 0,03076 & 0,20 & 0,93 \\
Té Verde & {$[1: 37]$} & 0,51278 & 0,21071 & 0,03512 & 0,23 & 1,00 \\
Yerba Mate & {$[1: 37]$} & 0,52134 & 0,19382 & 0,03230 & 0,12 & 0,86 \\
Manzanilla & {$[1: 37]$} & 0,53143 & 0,26776 & 0,04073 & 0,66 & 1,50 \\
Manz. Endulz. & {$[1: 37]$} & 0,63134 & 0,25926 & 0,04513 & 0,66 & 1,50 \\
\hline
\end{tabular}




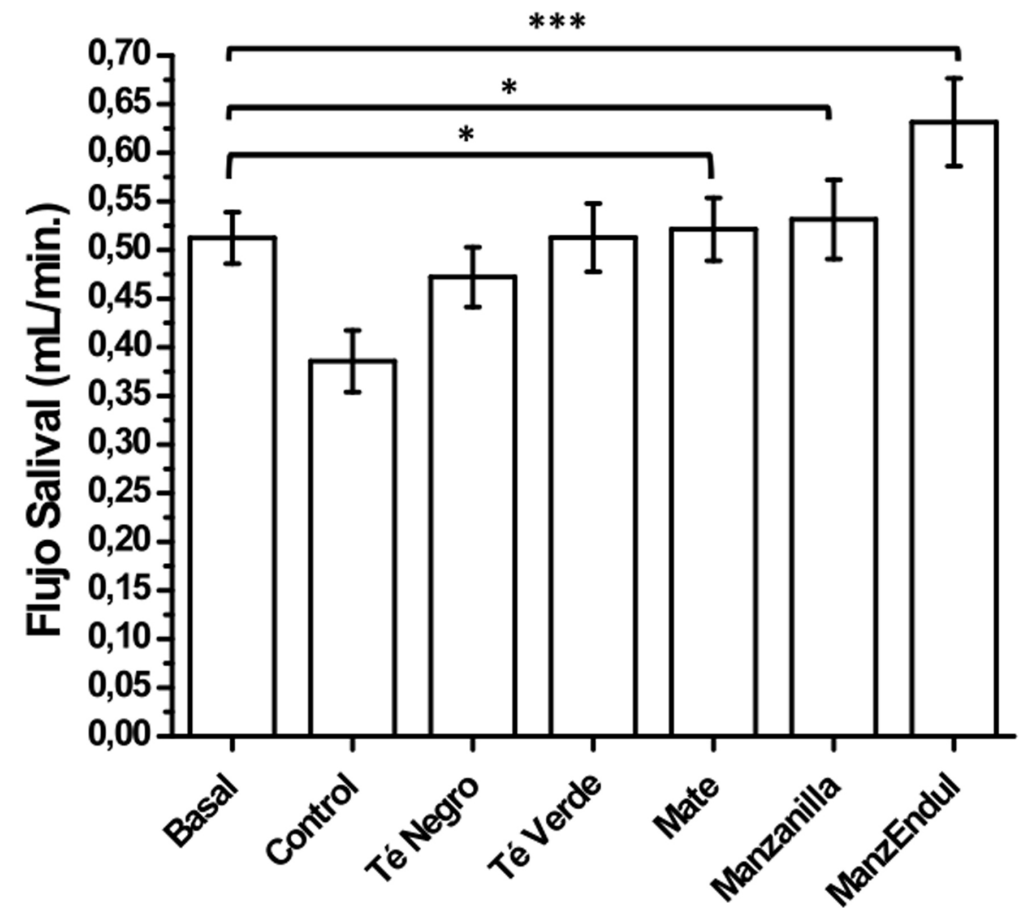

Fig. 2. Gráfico de Barras de Flujo Salival ( $\mathrm{ml} / \mathrm{min}$ ) posterior a la Ingesta de Infusiones, PromediotEE.

Tabla II. pH Salival posterior a la Ingesta de diferentes Infusiones, Promedios, Desviación Estándar (DE) y Error Estándar (EE).

\begin{tabular}{lcccccc}
\hline & & Promedio & \pm DE & tEE & Min. & Max. \\
\hline Basal & {$[1: 37]$} & 7,25054 & 0,23388 & 0,03845 & 6,84 & 7,69 \\
Control & {$[1: 37]$} & 7,29054 & 0,49568 & 0,08149 & 6,70 & 9,93 \\
Té Negro & {$[1: 37]$} & 7,18324 & 0,18864 & 0,03101 & 6,76 & 7,43 \\
Té Verde & {$[1: 37]$} & 7,25568 & 0,23050 & 0,03789 & 6,84 & 7,70 \\
Mate & {$[1: 37]$} & 7,17004 & 0,19564 & 0,04500 & 6,50 & 7,53 \\
Manzanilla & {$[1: 37]$} & 7,23233 & 0,23287 & 0,05300 & 6,66 & 7,67 \\
Manz. Endulz. & {$[1: 37]$} & 7,29676 & 0,20482 & 0,03367 & 6,83 & 7,63 \\
\hline
\end{tabular}

La ingesta de Manzanilla y Manzanilla con Endulzante arrojaron resultados de flujo salival significativamente mayores que los basales y los obtenidos post ingesta de agua, por lo cual es importante considerar que aunque el sabor fuera dulce o amargo (Wittig De Penna et al., 2002), y aun cuando al extracto de manzanilla se le han atribuido propiedades de astringencia (Mann \& Staba, 1986), el flujo va en aumento, posiblemente por la acción de algunos de los componentes de la manzanilla sobre los receptores en la mucosa oral.

pH Salival: Las diferentes infusiones presentan valores semejante (Tabla II). Pudimos observar que no existen diferencias significativas entre el $\mathrm{pH}$ salival
Basal con el estimulado mediante Placebo, Té Verde, Manzanilla y Manzanilla con Endulzante $(p \geq 0,05)$, mostrando que estas infusiones no modifican el pH de la saliva. En cambio el Té Negro $(7,18)$ y la Yerba Mate $(7,17)$ muestran un descenso significativo del $\mathrm{pH}$ salival $(p \geq 0,01)$ (Fig. 3).

El aumento del pH post ingesta de Té no mostró diferencias significativas al compararlo con el control y los parámetros basales de los sujetos. Esto podría explicarse porque a la temperatura de ingesta de la infusión de Té Verde $\left(50^{\circ} \mathrm{C}\right)$ el pH es 6,4 , cercano al neutro, y no alteraría el $\mathrm{pH}$ basal de la saliva de manera significativa. En el caso del Té Negro si observamos un descenso significativo en el pH. 


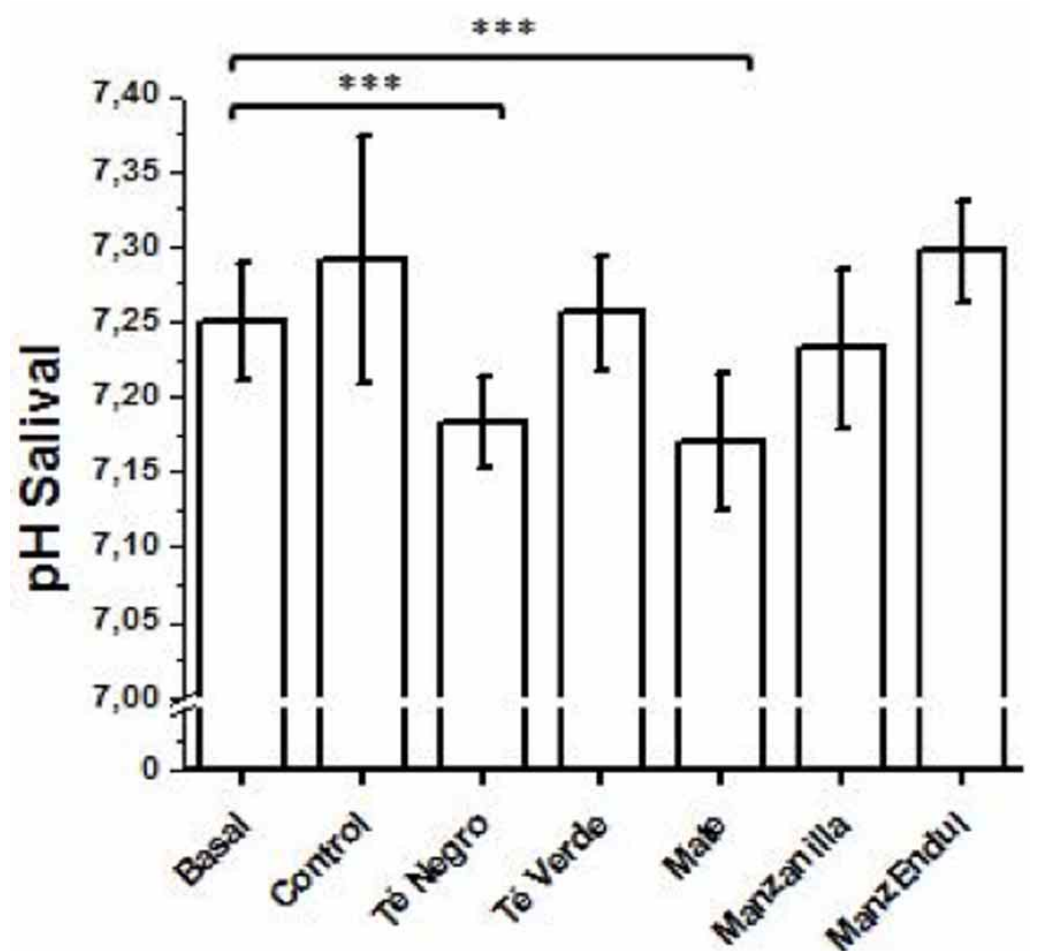

Fig. 3. Gráfico de Barras de pH Salival posterior a la Ingesta de Infusiones, Promedio $\pm E E$.

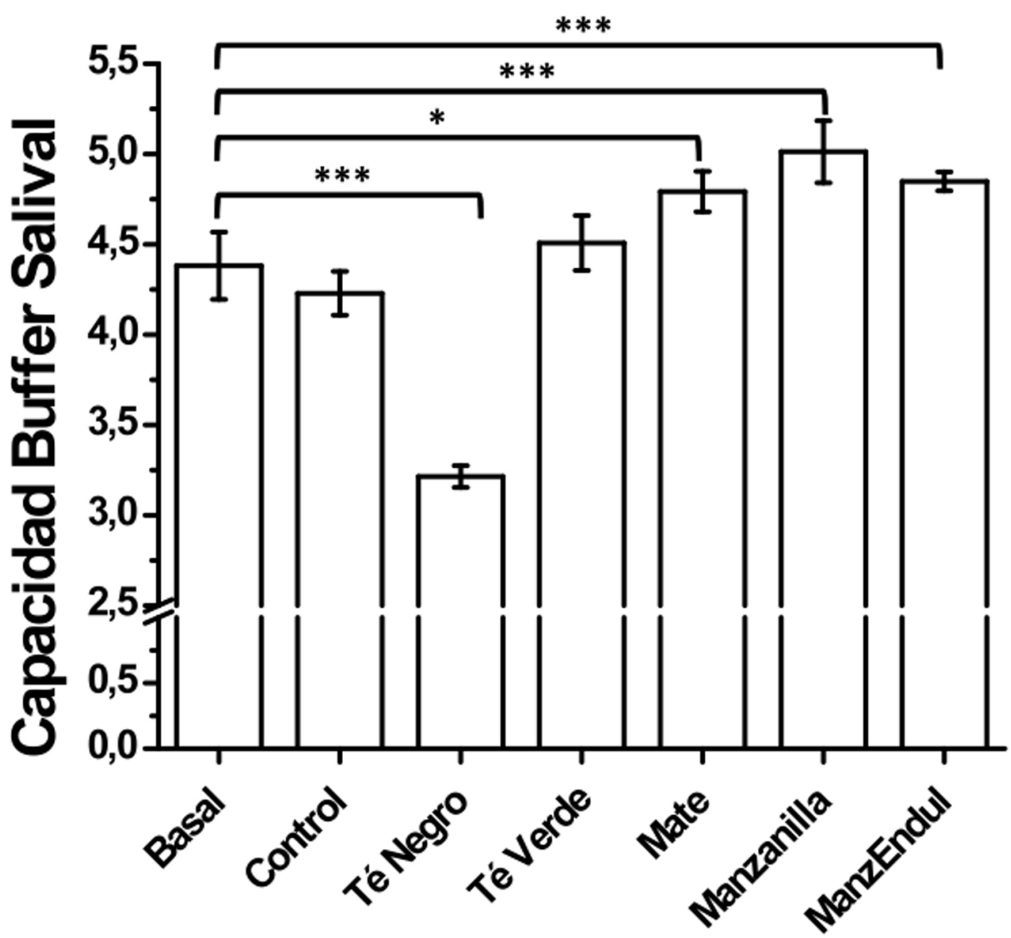

Fig. 4. Gráfico de Barras de Capacidad Buffer Salival posterior a la Ingesta de diferentes Infusiones, PromediotEE.
Al relacionar los valores de $\mathrm{pH}$ basal con los obtenidos post-ingesta de la Infusión de Manzanilla, no hubo entre ellos diferencias significativas, en cambio si hubo un aumento del $\mathrm{pH}$ posterior al consumo de una Infusión de Manzanilla con Endulzante, por lo que podemos inferir que la manzanilla no genera un riesgo para la integridad del diente.

Capacidad Buffer Salival: Se observó un incremento en sus promedios, destacando la Manzanilla $(5,01)$ y la Manzanilla con Endulzante $(4,84)$. El Té Negro mostró un marcado descenso en el promedio $(3,21)$ (Tabla III), lo que influye negativamente en la capacidad buffer salival $(p \geq 0,01)$, mientra que el Té Verde no influyó. La Yerba Mate $(p \geq 0,05)$ y especialmente la Manzanilla y Manzanilla con Endulzante incrementaron de manera significativa la capacidad buffer salival ( $p \geq 0,01)$ (Fig. 4).

Para el Té Verde, posiblemente por los valores de $\mathrm{pH}$ cercanos a los basales, no se produce ningún estímulo que logre aumentar significativamente la capacidad buffer salival. En el caso del Té Negro, como el pH no produjo un estímulo salival positivo como para aumentar el flujo salival por sobre los parámetros basales, la capacidad buffer tiende a disminuir, ya que cualquier circunstancia que disminuya el flujo salival tiende a disminuir su capacidad buffer (Heintze et al.), generando así un alto riesgo cariogénico.

En comparación con los resultados basales y placebo, los resultados obtenidos de capacidad buffer salival post-ingesta de Manzanilla y Manzanilla con Endulzante presentan diferencias estadísticamente significativas entre ambas muestras, lo que puede indicar que, descartando el sabor, alguno de los componentes liberados de la Manzanilla en forma de infusión podría generar el aumento en las concentraciones de uno o todos los sistemas responsables de la capacidad buffer salival. 
Tabla III. Capacidad Buffer Salival posterior a la Ingesta de diferentes Infusiones, Promedios, Desviación Estándar (DE) y Error Estándar (EE).

\begin{tabular}{lcccccc}
\hline & & Promedio & $\pm \mathrm{DE}$ & $\pm \mathrm{EE}$ & Min. & Max. \\
\hline Basal & {$[1: 37]$} & 4,38162 & 1,13592 & 0,18674 & 3,26 & 6,93 \\
Control & {$[1: 37]$} & 4,22892 & 0,73760 & 0,12126 & 3,05 & 5,81 \\
Té Negro & {$[1: 37]$} & 3,21405 & 0,36784 & 0,06041 & 2,78 & 4,03 \\
Té Verde & {$[1: 37]$} & 4,50730 & 0,92381 & 0,15187 & 3,08 & 6,41 \\
Yerba Mate & {$[1: 37]$} & 4,79231 & 0,35672 & 0,11213 & 2,68 & 5,78 \\
Manzanilla & {$[1: 37]$} & 5,01240 & 0,37485 & 0,17231 & 2,75 & 6,04 \\
Manz. Endulz. & {$[1: 37]$} & 4,84838 & 0,31984 & 0,05258 & 2,52 & 3,74 \\
\hline
\end{tabular}

\section{CONCLUSIONES}

El Té Verde no modifica ninguna de las propiedades salivales de manera significativa. A su vez el consumo de Té Negro no resulta beneficioso para ninguna de las características salivales, disminuye $\mathrm{pH}$ y capacidad buffer salival de manera significativa, aumentando con esto el riesgo cariogénico.

Tanto la Manzanilla como la Manzanilla con Endulzante muestran un aumento significativo en el flujo y la capacidad buffer salival. El aumento en el flujo posterior a la ingesta de alimentos generaría una mayor limpieza de los carbohidratos fermentables presentes en la dieta, a su vez el aumento en la capacidad buffer salival permite la restitución del pH a nive- les normales posterior a la producción de ácidos por parte de la placa bacteriana, pudiendo atribuirse a la Manzanilla una beneficiosa acción anticariogénica.

En el caso de la Yerba Mate, su consumo en bolsas no es habitual, su preparación más común depende del gusto de cada persona, por lo que se hace difícil estandarizar las muestras para realizar el estudio o promover su uso como agente anticariogénico. Aun así, posterior a su ingesta se obtuvieron aumentos estadísticamente significativos de flujo y capacidad buffer, sin embargo, también se apreció un descenso significativo del $\mathrm{pH}$, lo cual generaría una contradicción en su acción frente a la prevención de caries dental.

LARRUCEA, V. C.; HENRÍQUEZ, O. E.; INOSTROZA, T. M.; CAMPOS, M. L.; PEÑA, G. C.; LARRUCEA, S. C.; ARENAS, S. M. \& LARRUCEA, S. K. Immediate effect of commonly consumed Infusions in the salivary properties. Int. J. Odontostomat., 7(3):234-349, 2013.

ABSTRACT: A great number of the population consumes daily a variety of infusions such as Tea, Chamomile and Mate Herb. Different studies have determined their favorable effects in human beings, for this reason those infusions habitually used have been selected for this study, in order to characterize their immediate effects on the saliva properties. We studied groups of 37 healthy subjects, between 18-23 years of age, with low caries risk, and obtained 3 samples of non-stimulated saliva: Basal; Post-ingestion of Distilled Water (Placebo); Post-ingestion of Infusion (Black Tea, Green Tea, Mate Herb, Chamomile and Chamomile with Sucralose). All the tests were realized under standard conditions. We measured, salivary flow (ml/min); pH with pH-meter (PL-600, GOnDO Electronics Co, TW) and buffer capacity with Ericsson's method. All the information was processed with Anova Test in Origin 6.0. Our results showed the average of Salivary Basal Flow (0.51 ml/ $\mathrm{min}$ ) tends to increase standing out the effect of Chamomile with Sucralose $(0.63 \mathrm{ml} / \mathrm{min})$, the basal $\mathrm{pH}(7.25)$ was maintained relatively constant, and finally the Buffer Capacity (4.38) also tends to increase, emphasizing Chamomile (5.01). The effect of some infusions is positive on the salivary properties, emphasizing the Infusion of Chamomile, Chamomile with Sucralose and Mate Herb, which increase significantly the flow and the salivary buffer capacity. This suggests a favorable effect in the prevention of caries.

KEY WORDS: salivary flow, pH, buffer capacity, tea, chamomile, mate herb. 


\section{REFERENCIAS BIBLIOGRÁFICAS}

Azrak, B.; Callaway, A.; Knözinger, S. \& Willershausen, B. Reduction of the $\mathrm{pH}$-values of whole saliva after the intake of apple juice containing beverages in children and adults. Oral Health Prev. Dent., 1(3):229-36, 2003.

Bardow, A.; Madsen, J. \& Nauntofte, B. The bicarbonate concentration in human saliva does not exceed the plasma level under normal physiological conditions. Clin. Oral Investig., 4(4):245-53, 2000.

Beauchamp, J.; Caufield, P. W.; Crall, J. J.; Donly, K.; Feigal, R.; Gooch, B.; Ismail, A.; Kohn, W.; Siegal, M.; Simonsen, R. \& American Dental Association Council on Scientific Affairs. Evidence-based clinical recommendations for the use of pitand-fissure sealants: a report of the American Dental Association Council on Scientific Affairs. J. Am. Dent. Assoc., 139(3):257-68, 2008.

Burris, K.; Harte, F.; Davidson, M.; Stewart, N. \& Zivanovic, S. Composition and Bioactive Properties of Yerba Mate (llex paraguariensis A. St.-Hil.): A Review. Chilean J. of Agricultural R., 72(2), 2012.

de Almeida, P. V.; Grégio, A. M.; Machado, M. A.; de Lima, A. A. \& Azevedo, L. R. Saliva composition and functions: a comprehensive review. J. Contemp. Dent. Pract., 9(3):72-80, 2008.

de Oliveira, C. G.; Collares, E. F.; Barbieri, M. A. \& Fernandes, M. I. Production and concentration of saliva and salivary amylase in obese children. Arq. Gastroenterol., 34(2):105-11, 1997.

Ericson, D. \& Bratthall, D. Simplified method to estimate salivary buffer capacity. Scand. J. Dent. Res., 97(5):405-71, 1989.

Fenoll-Palomares, C.; Muñoz-Montagud, J.; Sanchiz, V.; Herreros, B.; Hernández, V.; Mínguez, M. \& Benages, A. Unstimulated salivary flow rate, $\mathrm{pH}$ and buffer capacity of saliva in healthy volunteers. Rev. Esp. Enferm. Dig., 96(11):773-83, 2004

Garcia-Godoy, F. \& Hicks, M. J. Maintaining the integrity of the enamel surface: the role of dental biofilm, saliva and preventive agents in enamel demineralization and remineralization. J. Am. Dent. Assoc., 139(Suppl.):25S-34S, 2008.

Heintze, U.; Birkhed, D. \& Björn, H. Secretion rate and buffer effect of resting and stimulated whole saliva as a function of age and sex. Swed. Dent. J., 7(6):227-38, 1983.

Humphrey, S. P. \& Williamson, R. T. A review of saliva: Normal composition, flow, and function. J. Prosthet. Dent., 85(2):1629, 2001.

Lamanda, A.; Cheaib, Z.; Turgut, M. D. \& Lussi, A. Protein buffering in model systems and in whole human saliva. PLoS One, 2(2):e263, 2007.
Llena-Puy, C. The rôle of saliva in maintaining oral health and as an aid to diagnosis. Med. Oral Patol. Oral Cir. Bucal, 11(5):E449-55, 2006.

López de Bocanera, M. E.; Koss de Stisman, M. A.; Bru de Labanda, E. \& Chervonagura de Gepner, A. Statistical analysis of salivary $\mathrm{pH}$ changes after the intake of black tea and yerba mate supplemented with sweeteners. J. Oral Sci., 41(2):81-5, 1999.

Mann, C. \& Staba, E. The Chemistry, Pharmacology, and Commercial Formulations of Chamomile. In: Craker, L. E. \& Simon, J. E. (Eds.). Herbs, Spices and Medicinal PlantsRecent Advances in Botany, Horticulture and Pharmacology. Phoenix, Oryx Pres, 1986. pp.235-80.

McKay, D. L. \& Blumberg, J. B. The role of tea in human health: an update. J. Am. Coll. Nutr., 21(1):1-13, 2002.

Simpson, A.; Shaw. L. \& Smith, A. J. Tooth surface $\mathrm{pH}$ during drinking of black tea. Br. Dent. J., 190(7):374-6, 2001.

Stookey, G. The effect of saliva on dental caries. J. Am. Dent. Assoc., 139(Suppl.):11S-17S, 2008.

Stookey, G.; Featherstone, J.; Rapozo-Hilo, M.; Schemehorn, B.; Williams, R.; Baker, R.; Barker, M.; Kaminski, M.; McQueen, C.; Amburgey, J.; Casey, K. \& Faller, R. The Featherstone laboratory $\mathrm{pH}$ cycling model: a prospective, multi-site validation exercise. Am. J. Dent., 24(5):322-8, 2011.

Szoke, E.; Máday, E.; Tyhák, E.; Kuzovkina, I. \& Lemberkovics, E. New terpenoids in cultivated and wild chamomile (in vivo and in vitro). J. Chromatogr. B Analyt. Technol. Biomed. Life Sci., 800(1-2):231-8, 2004.

Valenzuela, B. A. Tea consumption and health: beneficial characteristics and properties of this ancient beverage. Rev. Chil. Nutr., 31(2):72-82, 2004.

Vinson, J. A. Black and green tea and Heart disease: a review. Biofactors, 13(1-4):127-32, 2000.

Wittig De Penna, E.; Norambuena, L. M.; Negrete, C. R. \& Fuenzalida, M. R. Caracterizaciónn química y sensorial de tres tés digestivos. Nutrire, 24:7-19, 2002.

Dirección para Correspondencia:

Prof. Dr. Carlos Larrucea Verdugo MsC.

Departamento de Rehabilitacion Bucomaxilo Facial

Escuela de Odontologia, Facultad de Ciencias de la Salud Universidad de Talca

Avenida Lircay s/n, Talca

CHILE

Tel. 56-71-2201546

Fax: 56-71-2201761

Email: larrucea@utalca.cl
Recibido: 08-01-2013

Aceptado: 09-10-2013 